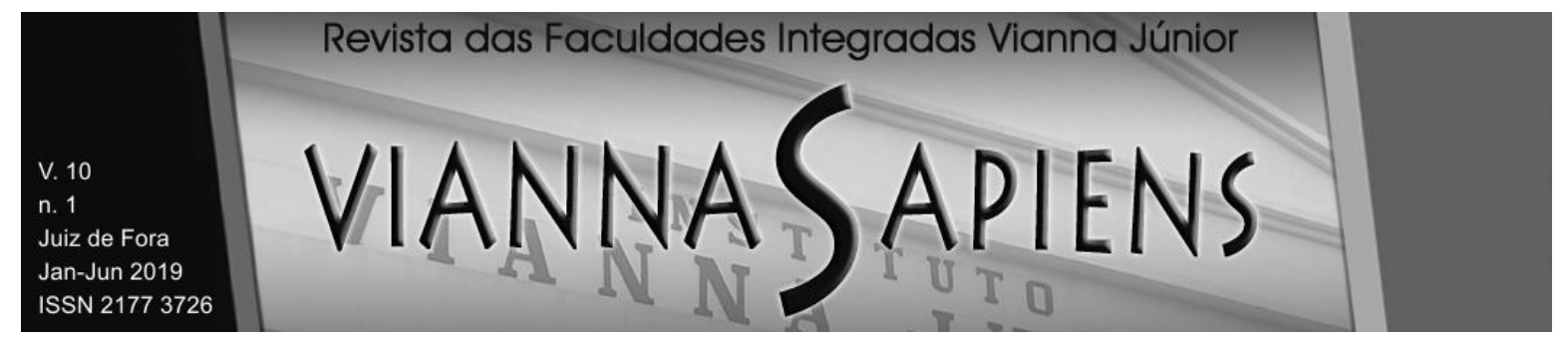

JUSTIÇA EM NÚMEROS:

ESTUDOS ACERCA DA (IN)EFICIÊNCIA DO PROCESSO JUDICIÁRIO

DOI: 10.31994/rvs.v10i1.473

Raphaella Neman de Novaes ${ }^{1}$

Leandro Guedes Bissoli ${ }^{2}$

\title{
RESUMO
}

Este artigo tem como objetivo analisar a forma pela qual as pessoas têm acesso ao Poder Judiciário, no tocante à possibilidade de concessão do benefício da gratuidade de justiça. Para isso, são correlacionadas questões como acesso à justiça, sobrecarga judiciária, morosidade processual, meios adequados de resolução de conflitos, bem como no tocante à eficiência ou não desse poder na resolução das suas inúmeras demandas. Assim, o referencial teórico aborda os temas acerca dos mencionados itens. Para tanto, os tipos de pesquisas utilizados foram bibliográfica e documental, ao amparo de doutrinas, leis e textos de autores que relatam sobre o tema. Ainda assim, foi realizada uma pesquisa de campo na Comarca de Juiz de Fora, Minas Gerais, nos processos físicos em trâmite, tendo como período análise o mês de abril de 2018. Concluiu-se, ainda, haver a necessidade de observância na concessão do benefício de Justiça Gratuita, o qual vem a afetar o acesso à justiça, e também pela utilização dos meios adequados de resolução de controvérsias.

\footnotetext{
${ }^{1}$ Graduanda no curso de Direito pelas Faculdades Integradas Vianna Júnior. E-mail: rapha_novaes_@hotmail.com. Número do registro no ORCID: 0000-0001-7863-1716.

${ }^{2}$ Graduado em Direito pelas Faculdades Integradas Vianna Júnior no ano de 2001. Mestre em Hermenêutica e Direitos Fundamentais pela Universidade Presidente Antônio Carlos no ano de 2013. E-mail: leandro@bittencourtebissoli.com.br. Número do registro no ORCID: 0000-0002-5005-9524.
} 


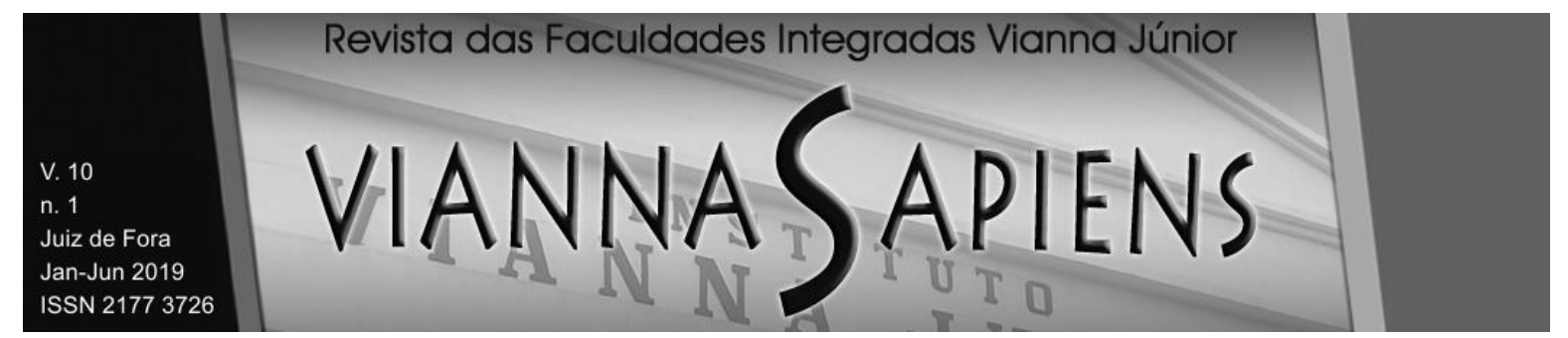

PALAVRAS-CHAVES: PODER JUDICIÁRIO. ACESSO À JUSTIÇA. JUSTIÇA GRATUITA. MEIOS ADEQUADOS. EFICIÊNCIA.

\author{
JUSTICE IN NUMBERS: \\ STUDIES ON THE (IN) EFFICIENCY OF THE JUDICIAL
}

\begin{abstract}
This article aims to demonstrate the people's access to the Judiciary, as well as the efficiency or not of it in the resolution of its numerous demands, correlating issues such as access to justice, deferral of Free Justice, judicial overload, procedural delays and adequate means of conflict resolution. Thus, the theoretical referential approaches the themes about the mentioned concepts. For this, the methods used were bibliographical and documentary research, under the protection of doctrines, laws and texts of authors that report on the subject, as well as a field research was carried out in the Juiz de Fora Region, Minas Gerais. It was also concluded that there is a need to comply with the concession of the Free Justice benefit, which affects access to justice, as well as the use of appropriate means of dispute resolution.
\end{abstract}

KEYWORDS: JUDICIARY POWER. ACCESS TO JUSTICE. FREE JUSTICE. MEANS SUITABLE. EFFICIENCY.

\title{
INTRODUÇÃO
}

O artigo que se desenvolverá visa analisar a forma pela qual as pessoas têm acesso ao Poder Judiciário, no tocante à concessão ou não do benefício da gratuidade de justiça, observando acerca da eficiência ou não desse poder na 


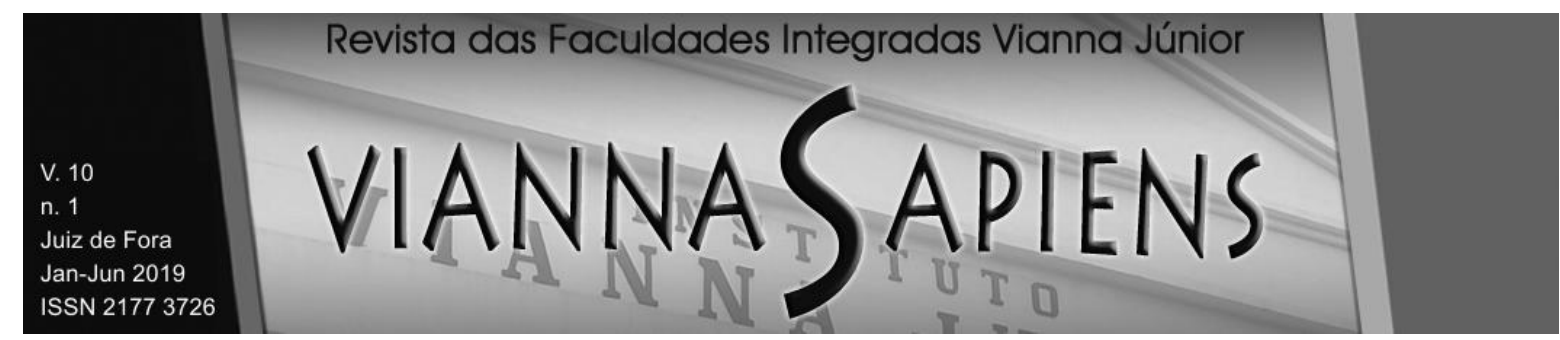

resolução das suas inúmeras demandas. Ainda assim, tem por finalidade questionar se existe uma facilidade para entrar com uma ação, afetando, dessa forma, o conceito em que se baseia o acesso à justiça e a efetividade da tutela jurisdicional.

Diante disso, a fim de que pudesse melhor ser analisado o Poder Judiciário, no tocante às questões expostas, a abordagem realizada no presente artigo será efetivada em estudo de pesquisas bibliográfica e documental, com análise de autores com notoriedade no assunto e importância para serem discutidos com seriedade, além de ser realizada uma pesquisa empírica nas Varas Cíveis da Comarca de Juiz de Fora, Minas Gerais, para melhor fundamentar a sobrecarga daquele poder. Com isso, a pesquisa de campo será realizada nos processos físicos em curso, tendo como base o mês de abril de 2018, perante as Varas Cíveis anteriormente citadas.

Com o escopo de uma melhor compreensão do tema, o presente trabalho será dividido em três tópicos. O primeiro relatará acerca da cultura do litígio no Brasil e seu avanço, bem como o direito ao acesso à justiça de forma efetiva, pelos indivíduos ao Judiciário, e como isso pode ser influenciado pela sobrecarga desse poder.

O segundo tópico, por conseguinte, mencionará acerca do deferimento da Justiça Gratuita e suas consequências, caso o mesmo venha a ocorrer de forma irrestrita. Desse modo, busca-se uma discussão acerca dos inúmeros processos nos quais as partes litigam sob os auspícios desse benefício, podendo relacionar mencionada questão à Economia, demonstrando a ideia de maximização dos lucros que os indivíduos possuem.

Por último, o terceiro item será desenvolvido acerca dos meios adequados de resolução de conflitos, de modo a demonstrar a importância deles. Diante disso, vem a indagar sobre a sobrecarga existente no Judiciário e a morosidade processual, haja vista muitas demandas poderem ser resolvidas pelos meios citados, tendo vista o advento do Código de Processo Civil de 2015.

Dessa forma, o tema pesquisado tem muito a contribuir para a melhoria da sociedade, uma vez que ela, de forma geral, acaba sendo afetada por essa cultura 


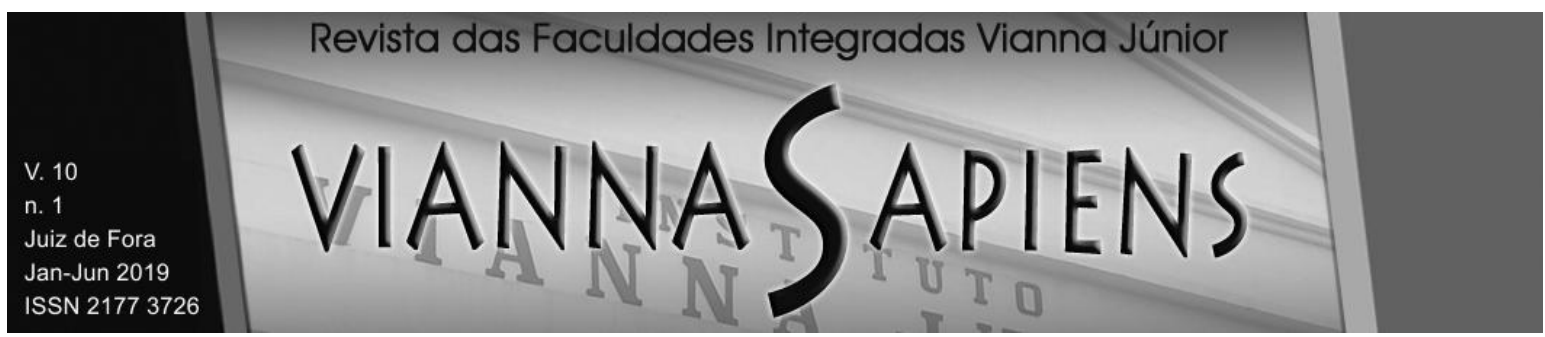

do litígio e, principalmente, pelo acesso à justiça, o qual é um direito fundamental garantido pela Constituição Federal de 1988, em seu art. 5ํ, inciso XXXV. Assim sendo, as situações e opções aqui desenvolvidas podem vir a contribuir com uma visão mais ampliada acerca da utilização do Poder Judiciário.

\section{ACESSO À JUSTIÇA}

Ao se iniciar por uma análise do Brasil, é de fácil percepção que a cultura do litígio ainda existe e persiste, mesmo com o advento do Código de Processo Civil de 2015, o qual veio a contribuir com a consolidação dos meios adequados de resolução de conflitos, como a Mediação, a Conciliação e a Arbitragem, e com as formas extrajudiciais e administrativas existentes.

Como o Brasil é um país democrático, o fato de existirem discordâncias é algo natural, o qual faz parte da própria essência humana, por mais que as divergências sejam em questões mínimas, o que depende do ponto de vista de cada pessoa. $\mathrm{O}$ problema é que, embora os impasses entre as pessoas estejam sempre presentes na sociedade, as questões colocadas aqui são baseadas em como os indivíduos lidam com eles e também pela cultura do litígio presente. Desse modo, como relatado por Marina Corrêa Dias (2015, p.1), "com o estímulo da competição, o diálogo foi ficando em segundo plano e estabeleceu-se a cultura do litígio, na qual sempre um sai ganhando e o outro perdendo".

Assim, segundo informações fornecidas pelo Conselho Nacional de Justiça (CNJ, 2018), na versão de 2018 do relatório "Justiça em Números", tendo como base os dados referentes ao ano de 2017, foi possível constatar que, embora o ano de 2017 tenha sido o de menor crescimento do estoque, com variação de $0,3 \%$, o Poder Judiciário finalizou o ano com um total de 80,1 milhões de processos que aguardam uma solução definitiva. O que significa um incremento de 244 mil casos pendentes em relação a 2016. Ainda, é importante ressaltar que em 2017, as despesas totais do Poder Judiciário somaram $R \$ 90,8$ bilhões, 4,4\% maior frente a 


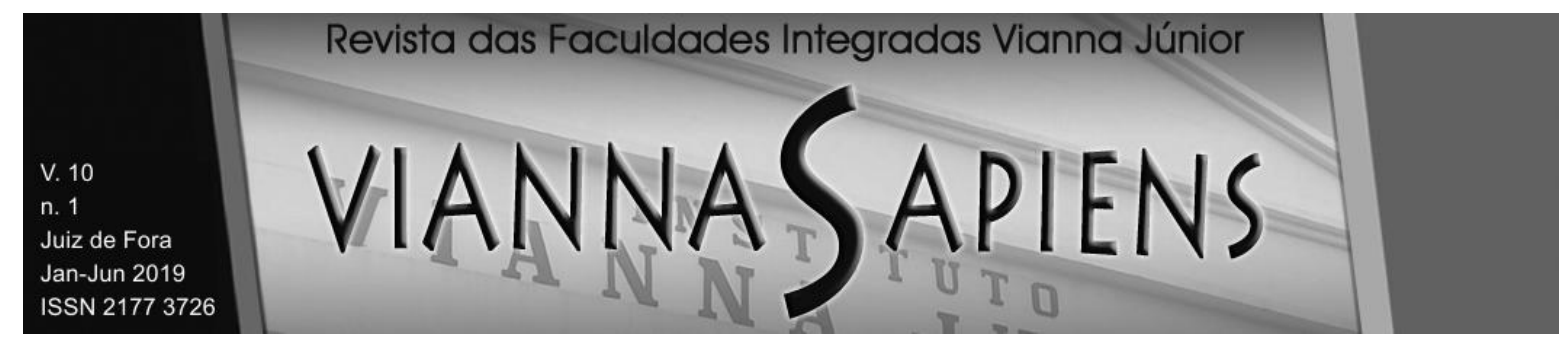

2016.

Dessa forma, ainda há que se falar em um número considerável de demandas no mencionado poder, o que acaba atingindo o acesso à justiça. Por conseguinte, em convergência com o exposto nos parágrafos anteriores, a cultura do litígio acaba resultando em uma busca por uma resposta do Judiciário, isto é, a busca por uma tutela jurisdicional.

No mesmo diapasão, ao ter a ideia de que tudo será resolvido por esse poder, cada vez mais, a máquina judiciária fica sobrecarregada. As pessoas, então, acabam acionando-o, a fim de terem seus problemas solucionados e, na maioria das vezes, não imaginam e nem mesmo pensam na questão do tempo e das custas processuais. Assim sendo, é necessário mencionar a quantidade de demandas existentes, além do crescente aumento delas, correlacionando, portanto, essa questão diretamente à demora para obtenção de um resultado.

Pela jurisdição ser inerte, para que se dela obtenha uma resposta, faz-se necessário provocá-la. O que vem acontecendo, no decorrer dos anos, conforme já exposto, é a tamanha procura pelo Judiciário. Isso acaba vindo a questionar o acesso à justiça, previsto no art. 5ํ, XXXV da Constituição Federal (1988), o qual menciona que "a lei não excluirá da apreciação do Poder Judiciário lesão ou ameaça a direito" e é conceituado da seguinte forma por Mauro Cappelletti e Bryant Garth (1988, p.8):

a expressão "acesso à Justiça" é reconhecidamente de difícil definição, mas serve para determinar duas finalidades básicas do sistema jurídico - o sistema pelo qual as pessoas podem reivindicar seus direitos e/resolver seus litígios sob os auspícios do Estado. Primeiro, o sistema deve ser igualmente acessível a todos; segundo, ele deve produzir resultados que sejam individual e socialmente justos.

Partindo, assim, do conceito relatado pelos autores descritos acima, há que se perguntar se realmente o sistema vem a ser acessível a todos e se o mesmo também vem a produzir resultados que sejam considerados justos. Isso porque, em 


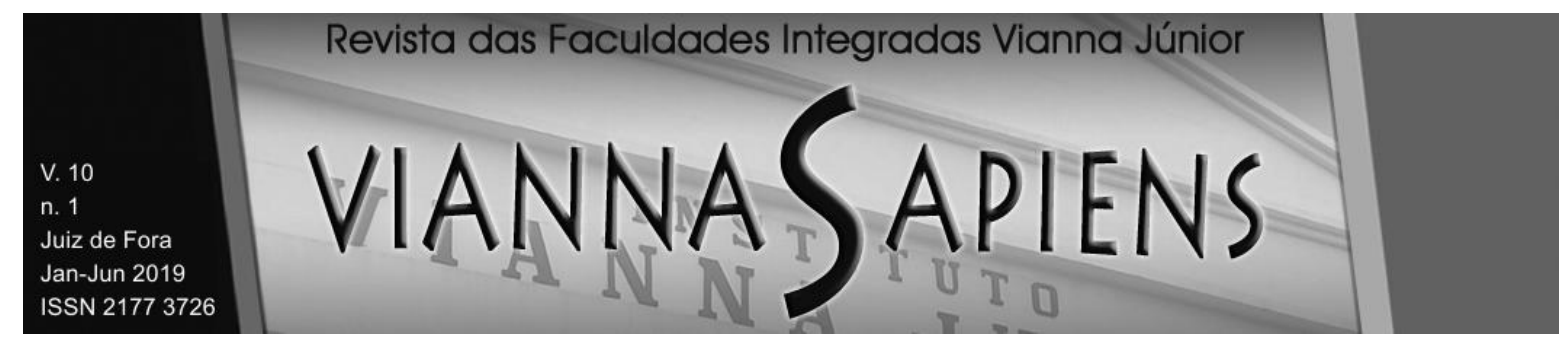

relação ao paradigma da justiça atual, é possível mencionar uma excessiva formalização, a falta de condições materiais e a disparidade no contexto social, acabando por excluir tal acesso a todos os cidadãos, segundo colocado por Roberta Freitas Carvalho Santos (2012).

Ainda, conforme supramencionado, o acesso à justiça é tido como um princípio fundamental, isto é, uma garantia dada pelo Ordenamento Jurídico Brasileiro à sociedade e, nos dizeres de Mauro Cappelleti e Bryant Garth (1988), há que se entender que o direito ao acesso à justiça deve ser efetivo.

Assim, citando as duas finalidades básicas do sistema jurídico, expostas pelos autores acima relatados, a questão colocada não é somente fazer com que as pessoas consigam entrar com uma demanda, mas também obter uma resposta efetiva e eficaz, bem como obter respostas justas, as quais devem ser realizáveis. No mesmo sentido, é o entendimento de Roberta Freitas Carvalho Santos (2012, p.4):

falar em justiça requer a análise das características que compõem a sua gênese, a saber: a equidade, a legitimidade e, sobretudo, a moralidade e todos os demais valores éticos. Assim, não se pode construir um verdadeiro sistema de justiça sem se falar em cidadania e mais além, sem se questionar que sociedade contemporânea, altamente complexa, reclame o oferecimento de condições materiais que tornem esse direito humano fundamental realizável, bem como que esse sistema esteja efetivamente impregnado de participação democrática.

Por conseguinte, o acesso à justiça vai muito além de propor uma ação, incluindo a obtenção de uma resposta pelo Judiciário, resposta esta que deve ser efetiva. Assim, conforme Luiz Wambier (2007, p.321) menciona, "garantir às pessoas a tutela jurisdicional e prestar-lhes a tutela inefetiva e ineficaz é quase 0 mesmo que não prestar a tutela". A efetividade deve ser ao ponto de a pessoa ter sua demanda resolvida, de terem sido respeitados os princípios basilares do processo, como o contraditório, a ampla defesa e a duração razoável, para que, assim, não ocorram incertezas acerca da neutralidade desse poder. 


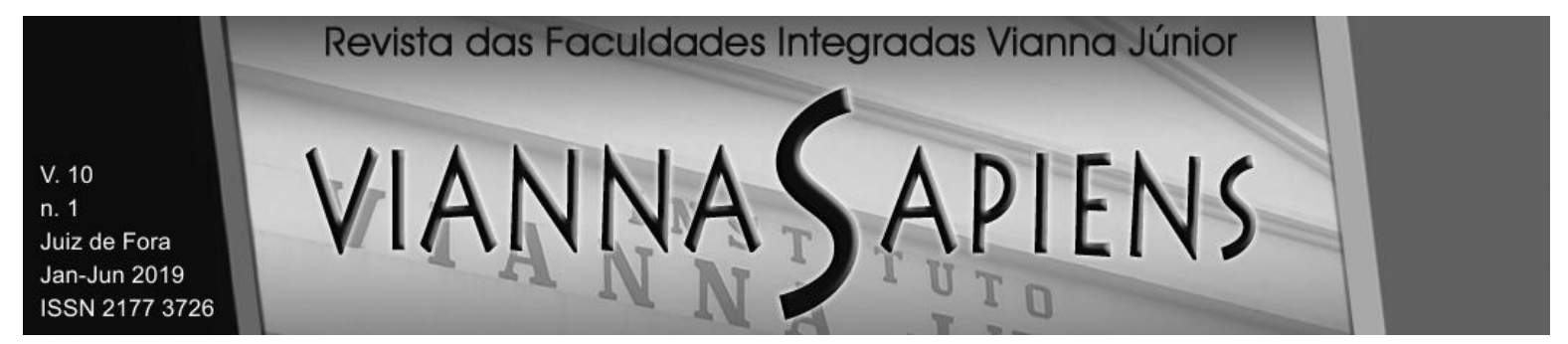

Ademais, segundo relatado por Ana Flavia Melo Torres (2002, p.1):

falar em acesso à ordem jurídica justa é também falar em justiça eficaz, que é um dos maiores problemas dos sistemas jurídicos de hoje. A terminologia JUSTIÇA está diretamente ligada a não só "dar a cada um o que é seu" mas sim em "dar a cada um o que é seu conforme a vontade da lei e em seu devido tempo".

Todavia, empecilhos acabam acontecendo, afetando, assim, o princípio constitucional que garante 0 acesso à justiça. Isso porque se sabe que há uma morosidade na obtenção de resposta pelo poder Judiciário, não falando somente na prolação de uma sentença, mas também em relações a despachos e decisões. E um dos motivos que acaba vindo a dar causa para que isso venha a ocorrer são as inúmeras demandas existentes.

Ao se falar em morosidade processual, é necessário também mencionar a sobrecarga da máquina judiciária, uma vez que a primeira é decorrência da segunda. O exposto no parágrafo anterior tem total correlação com essas duas questões, haja vista que a efetividade do Judiciário acaba vindo a ser afetada por essas razões, já que, embora as pessoas venham se conscientizando acerca de outros meios de terem seus problemas solucionados, ainda são muitas que nem sequer pensam nisso.

Dessa forma, quanto mais os cidadãos acionam o Judiciário, mais as Varas ficam sobrecarregadas de processos. A questão aqui colocada não tem por bem discutir se as partes têm ou não direito de propor uma demanda, mas sim relatar que, com a quantidade existente, o acesso à justiça vem a ser afetado. Por conseguinte, muitas ações acabam ficando sem movimentação em razão dessa sobrecarga.

Tem-se, então, que "a morosidade processual é um problema que aflige o Poder Judiciário Brasileiro há tempos. Com o intuito de solucionar tal problema, este foi elevado ao nível constitucional com a Emenda Constitucional $n^{\text {a }} 45$ ", como relatado por Renato Souza Mendes (2012, p.1). Com essa emenda, mudanças na máquina estatal aconteceram, sendo, pois, acrescentado ao art. 5o o princípio da duração razoável do processo, com o objetivo de extinguir essa morosidade 


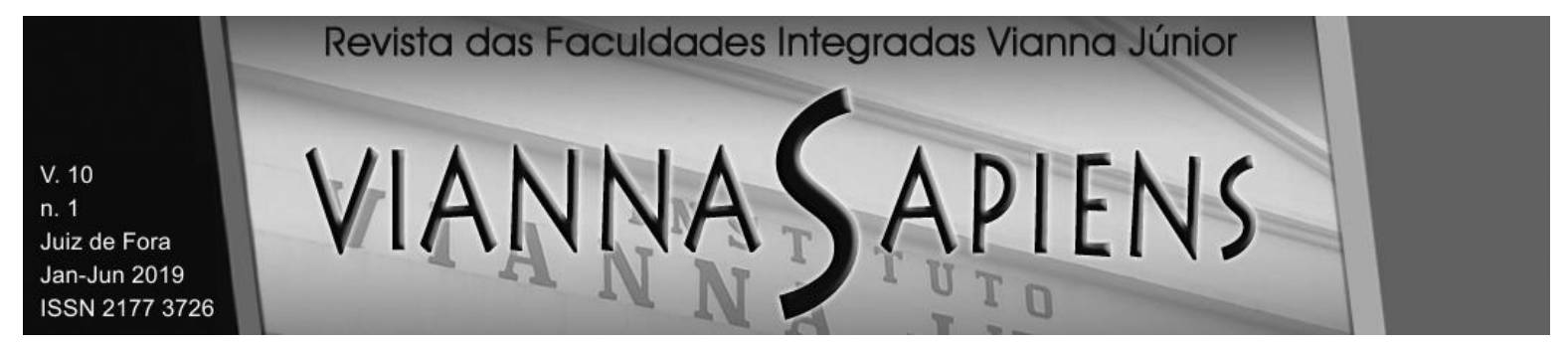

existente.

Na mesma toada segue o jurista Nagib Slaibi Filho (2005, p.19), mencionando que:

a norma garante mais que o direito de ação ou de acesso ao judiciário, mas a sua eficiência, celeridade e tempestividade. Poderse-ia dizer que a norma declara o direito fundamental de todos à eficiente realização do processo pelo qual se leva o pedido à cognição judicial ou administrativa: é assim, direito ao processo eficiente, muito além do simples direito ao processo.

Seguindo o entendimento supramencionado, bem como em decorrência do já exposto anteriormente, devem existir as garantias de eficiência, celeridade e tempestividade, significando, portanto, a prestação da tutela jurisdicional dentro de um prazo razoável, já que, para muitos cidadãos, uma justiça que não cumpre suas funções observando isso acaba sendo uma justiça inacessível, como sintetizado por Cappelletti e Garth (1988).

Ainda assim, não existe um tempo determinado que venha a ser considerado geral e seguido para que todos os processos tenham seu fim, devido à peculiaridade de cada caso. Isso acontece porque existem ações que vão demandar uma dilação probatória maior, uma produção de diversos tipos de provas, e, por outro lado, outras serão mais simples, de forma a poderem ser resolvidas em um tempo menor. Ademais, faz-se necessário mencionar que não somente o juiz é responsável pelo andamento do processo, mas também as partes, devidamente representadas por seus respectivos advogados.

Como colocado por Humberto Theodoro Junior (2005, p.22-23),

o processo, instrumento de atuação de uma das principais garantias constitucionais - a tutela jurisdicional -, teve de ser repensado. É claro que, nos tempos atuais, não basta mais ao processualista dominar os conceitos e categoriais básicos do direito processual, como a ação, o processo e a jurisdição, em seu estado de inércia. $O$ processo tem, sobretudo, função política no Estado Social de Direito. Deve ser, destarte, organizado, entendido e aplicado como instrumento de efetivação de uma garantia constitucional, 


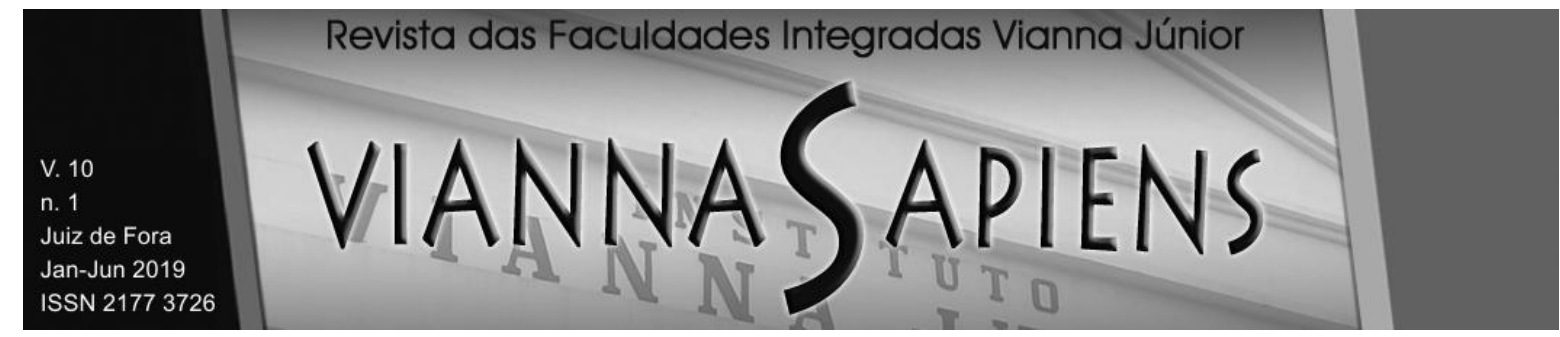

assegurando a todos o pleno acesso à tutela jurisdicional, que há de se manifestar sempre como atributo de uma tutela justa.

Dessa forma, há que se mencionar a necessidade de o processo ser um meio que garanta a efetividade da tutela jurisdicional à parte, visando questões justas, bem como o direito de se obter uma resposta através do Poder Judiciário, o que ainda, para muitas pessoas, é considerada a solução para seus problemas.

\section{O DEFERIMENTO DA JUSTIÇA GRATUITA}

Sabe-se que o benefício da Justiça Gratuita é cabível às partes que não possuem condições de arcar com as custas processuais, uma vez que suas condições econômicas não permitem tal possibilidade, como previsto no art. 5ำ, inciso LXXIV da Constituição Federal (1988), o qual relata que "o Estado prestará assistência jurídica integral e gratuita aos que comprovarem insuficiência de recursos", sendo, pois um direito fundamental.

No mesmo diapasão, conforme conceituado por Schiavi (2009, p.288), a Justiça Gratuita "é o direito à gratuidade das taxas judiciárias, custas, emolumentos, despesas com editais, honorários de perito, etc., ou seja, não terá a parte um advogado fornecido pelo Estado, mas não pagará as despesas do processo". E, em consonância com o exposto, a parte fica dispensada provisoriamente do pagamento de tais despesas. Isso ocorre porque, no desenrolar do processo, esse benefício pode vir a ser revogado. Assim, tal benefício refere-se à gratuidade das despesas processuais.

Dessa forma, para que as pessoas que não possuem mencionada condição deixem de propor uma ação, renunciando seus direitos, o Estado veio a determinar a possibilidade de concessão desse benefício. Todavia, a real necessidade da parte deve ser comprovada de uma forma ampla, a fim de que as pessoas que realmente precisam de mencionado benefício sejam atendidas. Desse modo, alguns requisitos 


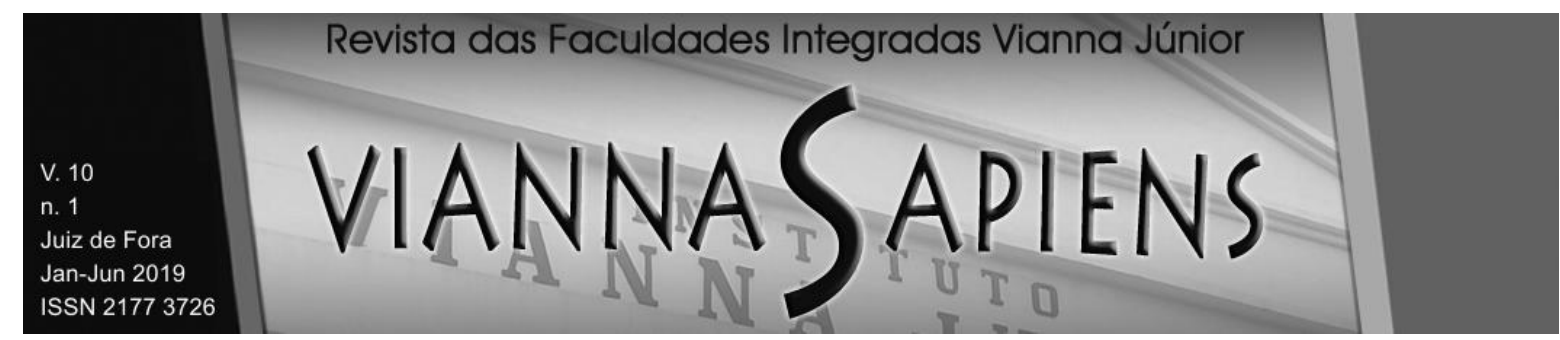

devem ser observados ao mencionar a Justiça Gratuita, porque é necessário saber a profissão da parte, sua condição salarial e também deve haver uma declaração de hipossuficiência, devidamente assinada.

Por conseguinte, é de notório conhecimento que esse benefício acaba trazendo vantagens para a parte economicamente hipossuficiente, uma vez que a mesma não arcará com as custas do processo. E, isso significa que não recolherá verba indenizatória para cumprimento de citação, penhora, não pagará honorários periciais, verba para o cumprimento de decisão pelo oficial de justiça e nem mesmo honorários de sucumbência, pois essa cobrança acaba ficando suspensa pelo prazo de 05 (cinco) anos, dentre outros exemplos.

As vantagens mencionadas anteriormente podem ser assim consideradas como algo benéfico para o cidadão que está sob os auspícios da Justiça Gratuita, já que, na maioria das vezes, este não conseguiria litigar se não possuísse o mencionado benefício.

Todavia, o que vem acontecendo no Poder Judiciário são os inúmeros deferimentos de Justiça Gratuita, de uma forma crescente. Certo é que muitas são as pessoas que precisam de mencionado benefício e que, para acessarem esse poder e exercerem o acesso à justiça, direito fundamental trazido pela Constituição Federal de 1988, mencionada questão faz-se necessária.

Ainda assim, embora muitas pessoas realmente precisem, muitas que possuem esse benefício teriam condições de arcar com as custas dos seus processos. Como colocado também por Arthur Monteiro Minotto (2014), a concessão da justiça gratuita não é para possibilitar à parte economia no tocante à manutenção do seu padrão de vida, mas sim para que o direito a acesso à justiça seja realmente atingido aos que não possuem meios para tanto.

Dessa forma, seguindo essa linha de raciocínio, conforme conceituado por Fernandez (2013, p.1):

a falta de restrições no que se refere à gratuidade da justiça provoca uma sobrecarga e delonga processual que se traduz, em termos 


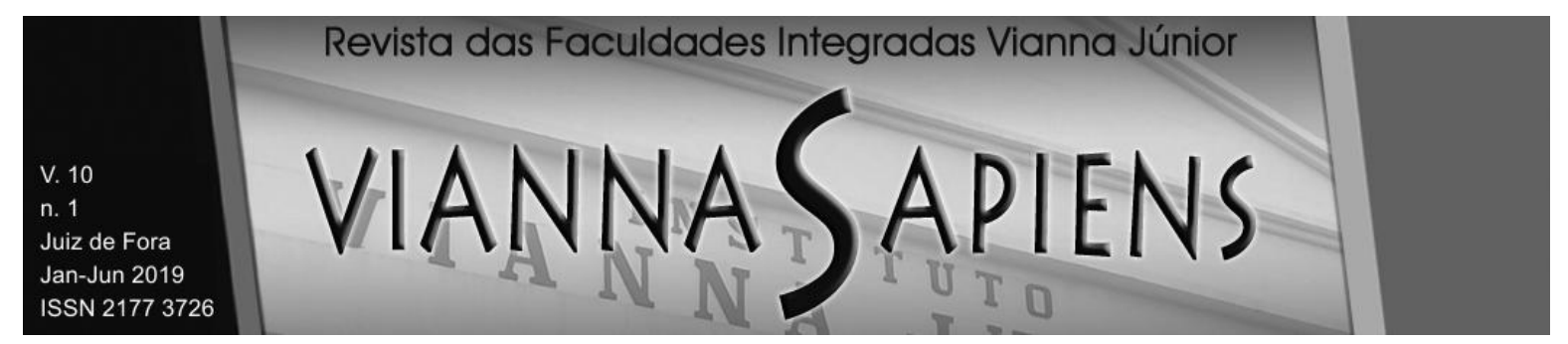

econômicos, em um preço ao litígio, encarecendo-o e excluindo, em última instância, aos setores realmente pobres da sociedade.

Assim, na toada do pensamento dos dois autores demonstrados, a essencialidade da obtenção da Justiça Gratuita deve ser observada, para que o princípio fundamental e basilar do acesso à justiça seja respeitado e cumprido. Temse, portanto, que, o deferimento de mencionado benefício deve ser observado de formas precisa e detalhada, a fim de que não ocorra o encarecimento desse princípio às pessoas que efetivamente precisam, analisando, ainda, a questão da proporcionalidade, já que quanto mais for concedida Justiça Gratuita, sem observância do relatado anteriormente, mais as partes vão procurar o Judiciário, aumentando, assim, a sobrecarga e a morosidade processuais.

Diante disso, para uma melhor demonstração sobre o tema, ao se fazer uma pesquisa de campo, a qual demonstra o resultado sobre os processos físicos em trâmite nas Varas Cíveis da Comarca de Juiz de Fora, Minas Gerais, obtida através de consulta ao sistema forense, fez-se possível constatar que mais da metade, mais precisamente $72 \%$ (setenta e dois por cento) das partes que estão litigando, está sob os auspícios da Justiça Gratuita/ Assistência Judiciária. Esse número acaba vindo a requerer um pouco de atenção, por ser uma porcentagem considerável.

Desse modo, $72 \%$ é um número que deve ser levado em consideração, a fim de que seja refletido se realmente todas as partes que possuem mencionado benefício precisam deste de uma forma efetiva, já que, como exposto ao decorrer desse artigo, isso acaba contribuindo com a demora de uma resposta eficaz, dentro de um prazo útil e razoável pelo Judiciário. Ainda assim, a questão aqui colocada visa demonstrar que, embora muitos cidadãos se utilizem da justiça gratuita, ao observar suas condições econômicas, eles teriam como arcar com as custas processuais, sem prejuízo de seus sustentos e de suas famílias.

Ademais, estendendo e correlacionando esse assunto à Economia, muito há que se falar sobre a relação que ambos possuem, uma vez que, ao se iniciar pelo conceito da Análise Econômica do Direito, tem-se que esta é tida como "a análise 


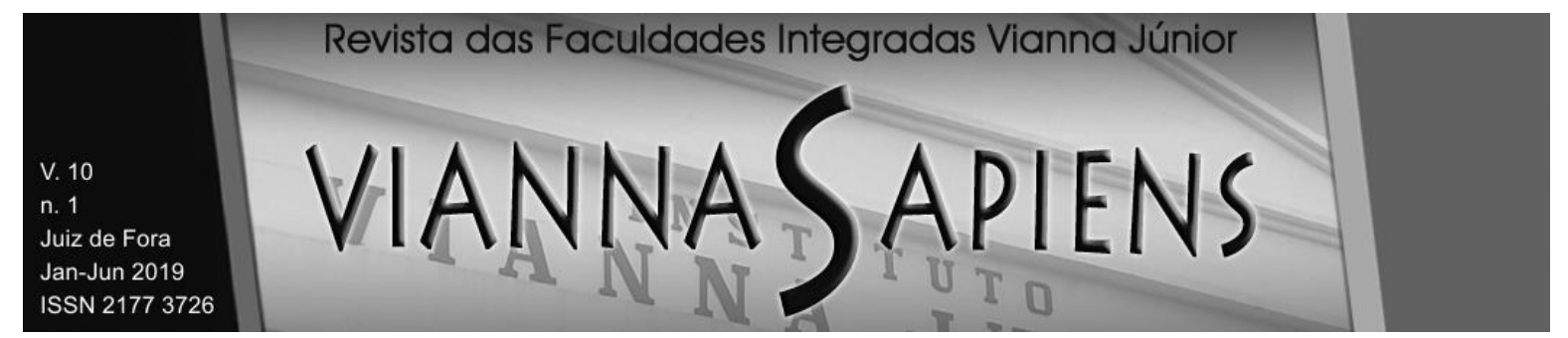

das normas jurídicas como uma estrutura de incentivos para os agentes que a elas estão subordinados ou voluntariamente a ela se subordinam", segundo Eric Almeida Carro (2016, p.1). Isso significa que o Poder Judiciário acaba sendo considerado um meio pelo qual as pessoas se subordinam, uma vez que visam incentivos para se chegar a ele. Incentivos esses que podem ser considerados a maximização racional de seus lucros, tendo como um de seus objetivos a obtenção de Justiça Gratuita, reduzindo, ainda, seus custos de transação.

Desse modo, ao relatar sobre o que poderia ser considerada maximização racional de lucros e o motivo para esta questão estar ligada ao deferimento de Justiça Gratuita, gerando uma sobrecarga no Judiciário, conforme relatado por Bruno Meyerhof Salama (2008, p.17):

\begin{abstract}
a adoção do conceito de maximização racional indica que, na formulação de teorias, se partirá da premissa de que os indivíduos calculam para alcançarem os maiores benefícios aos menores custos. Assim, a suposição será a de que o comportamento observado de cada indivíduo refletirá a busca de seus objetivos através dos meios disponíveis.
\end{abstract}

Seguindo o entendimento supramencionado, tem-se, então, que as pessoas, senão em tudo que fazem, buscam saber se suas ações resultarão em benefícios maiores do que os custos que tiveram. Por isso, ao entrar com uma ação, embora tenha condição de arcar com as custas processuais, o indivíduo acaba requerendo a concessão desse benefício, visto que está pensando na maximização de seu bemestar, bem como na questão de que, se concedido, obterá lucros, que serão maiores que seus custos, já que muitas vezes somente arcará com os honorários contratuais do advogado, por exemplo.

Ainda, na mesma linha de raciocínio, tem-se a teoria dos custos da transação, ou seja, o objetivo aqui é a minimização dos custos. Dessa forma, a justiça gratuita acaba se encaixando nesse conceito, porque faz com que as pessoas tenham menos gastos. Todavia, essa teoria também é baseada em riscos, haja vista que, conforme entendimento de Ricardo Thielmann (2013, p.2), 


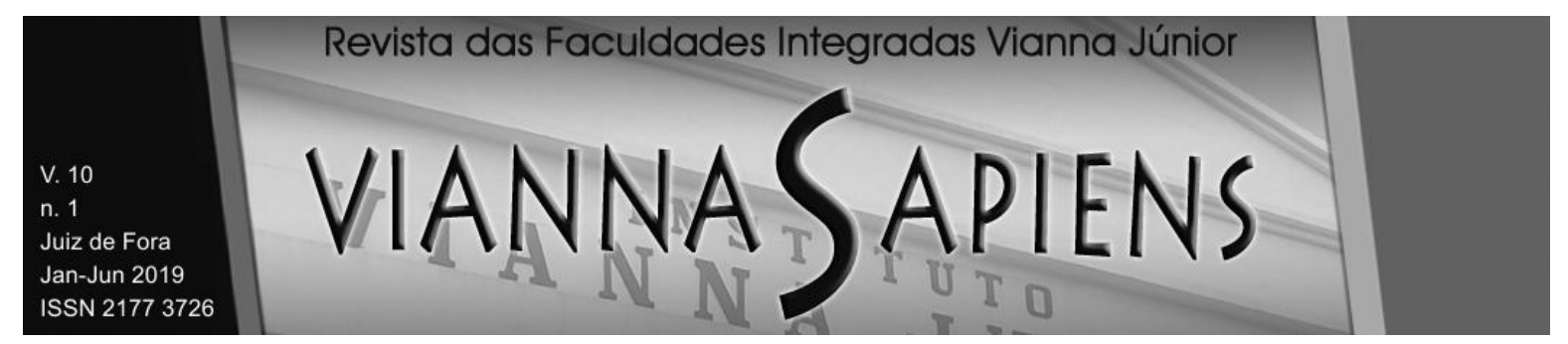

os custos de transação seriam determinados pelas incertezas envolvidas no processo de transacionar, pela freqüência das operações realizadas e pelo grau de especificidade dos ativos. Entende-se por incerteza como a impossibilidade de identificar todos os aspectos relevantes que podem vir a ocorrer e que afetam uma transação.

Assim, as incertezas podem ser baseadas na questão de que, quando a parte requer a concessão do benefício da Justiça Gratuita, a fim de não arcar com as custas processuais, os riscos acabam sendo inerentes, uma vez que o juiz poderá não deferir mencionado pedido. Em consequência, esse não deferimento acaba vindo a afetar o indivíduo, já que o mesmo poderá ou não continuar com a demanda processual, todavia, é também uma hipótese, a qual deveria ter sido considerada por ele, ao entrar com a ação.

Portanto, como exposto, os benefícios trazidos pelo não pagamento das custas é enorme, o que faz com que ainda mais pessoas procurem esse poder, a fim de terem seus conflitos resolvidos, sendo correlacionado, assim, à maximização de seus lucros e à diminuição de seus custos, por haver a busca pelo bem-estar.

\section{UMA NOVA PERSPECTIVA}

Conforme disposto nos artigos do Código de Processo Civil (2015), a se exemplificar o art. 319, na própria petição inicial, deverá ser mencionado o interesse por um dos meios adequados de resolução de conflitos, conforme exposto:

Art. 319. A petição inicial indicará:

VII - a opção do autor pela realização ou não de audiência de conciliação ou de mediação.

Ainda assim, mesmo com o citado requisito da petição inicial, muitos autores acabam optando pela não escolha da audiência, ou por não entender ser uma boa opção ou também para que o processo corra mais rápido. 


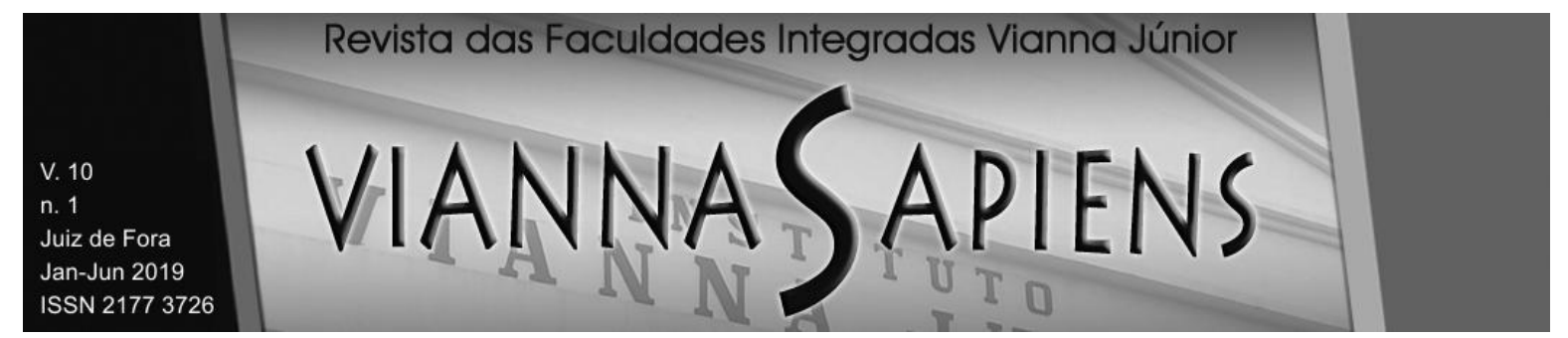

Por conseguinte, as pessoas acabaram se acostumando com a questão de procurar o Judiciário para terem seus conflitos solucionados, de modo a colocar suas expectativas e interesses em um terceiro, que, muitas vezes, nem sequer já tenham visto. É sabido que o juiz é uma pessoa muito capacitada, tendo estudado para estar no cargo que ocupa, todavia, ao procurar o citado poder, as pessoas retiram de si, na maioria das vezes, seu poder de decisão própria.

No mesmo diapasão, ao ter a ideia de que tudo será resolvido pelo Poder Judiciário, cada vez mais, a máquina judiciária fica sobrecarregada. Os indivíduos, então, acabam acionando o citado poder, a fim de terem seus problemas solucionados e, na maioria das vezes, não imaginam e nem mesmo pensam na questão do tempo e das custas processuais, como expostas nos tópicos anteriores deste artigo. No mesmo sentido é o entendimento de Adriane Medianeira Toaldo (2018, p.1), uma vez que:

no momento em que se configura a lide, de uma forma quase que instantânea, as partes buscam o resultado desejado através do Poder Judiciário, deixando de lado possibilidades nas quais poderiam solucionar seus conflitos de maneira mais célere, e com menos gastos.

Nesse sentido, em consideráveis vezes, essa máquina fica sobrecarregada de processos que poderiam ser resolvidos por outros meios, conforme os relatados no início desse trabalho, como a Mediação, a Conciliação e a Arbitragem, consolidados pelo CPC de 2015. Dessa forma, tem-se que processos como os que envolvem questões familiares, nos que há continuidade, tendo as partes contato, são ideais para a Mediação, por exemplo. Por outro lado, para as relações que são pontuais, o caminho seria a Conciliação.

Ao observar, assim, o que muito ainda precisa ocorrer é a necessidade de se ter uma visão mais ampliada, buscando, também, outros meios a fim de que os impasses possam ser solucionados e, principalmente, visando a efetividade e a satisfação de todas as pessoas envolvidas na relação. 


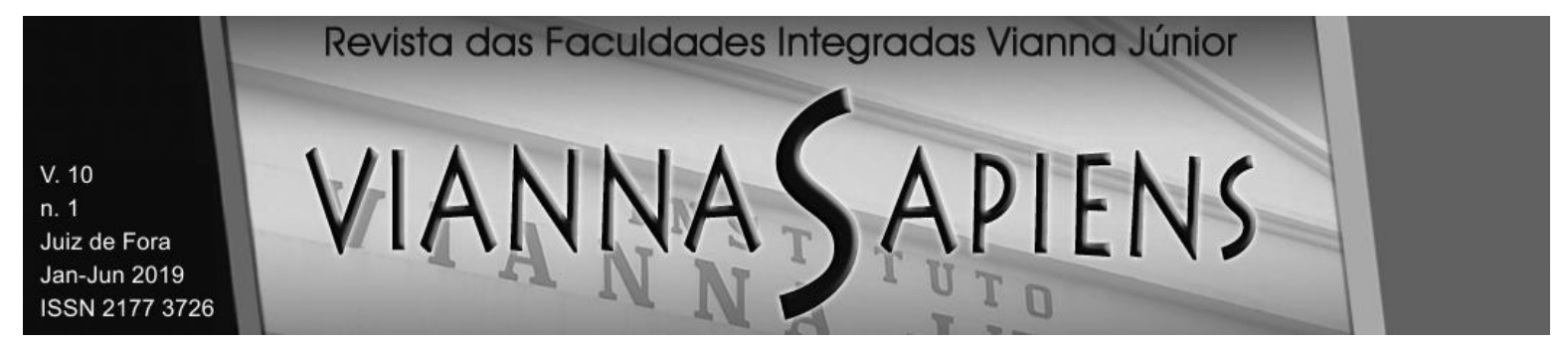

Por conseguinte, não há que se relatar ser certo ou errado propor uma demanda no Judiciário. O mencionado aqui é a questão de que nem todas as situações a serem resolvidas pelas partes precisam ter como objetivo o citado poder. Assim sendo, é necessário mencionar a quantidade de demandas existentes e o crescente aumento dessas, correlacionando, portanto, essa questão diretamente à demora para obtenção de uma resposta, uma vez que o acesso à justiça também vem a ser afetado.

A sociedade já possui o costume de procurar o Judiciário em primeiro lugar, e, utilizando o direito comparado, a fim de se fazer uma observação, conforme o jurista Sílvio de Salvo Venosa (2012, p.70) coloca, tem-se que:

no direito chinês, antes de se chegar a um processo judicial, tentamse todas as formas de conciliação, pois existem muitos grupos sociais dispostos a conciliar os antagonistas, como os municípios e as próprias famílias. Mesmo quando já se conseguiu uma decisão favorável em Juízo, reluta-se em executá-la; quando executada, procede-se de forma que prejudique o adversário o mínimo possível. Esses são os pensamentos tradicionais chineses, de acordo com a doutrina de Confúcio, tão distantes de nosso entendimento ocidental.

O Código de Processo Civil de 2015 acabou se aproximando um pouco do pensamento do jurista acima, já que consolidou os meios adequados de resolução de conflitos, colocando, ainda, a importância deles para a solução dos impasses presentes na sociedade. Isso também colaborou para que as pessoas diminuíssem a busca pelo Judiciário, fato que possibilitou uma melhoria nesse poder, em questões de tempo e sobrecarga.

Assim, embora consolidado pelo CPC de 2015, a necessidade de as pessoas terem seus pensamentos melhorados e visões ampliadas ainda existe, pois a cultura do litígio e a ideia de o juiz ser o único a resolver conflitos ainda se faz presente. Por isso, faz-se essencial e indispensável a ajuda dos advogados, juristas e operadores do direito, a fim de demonstrar que os meios adequados de resolução de conflitos são opções favoráveis e muito satisfatórias.

Tal fato é ocasionado porque, através da Mediação, os próprios indivíduos 


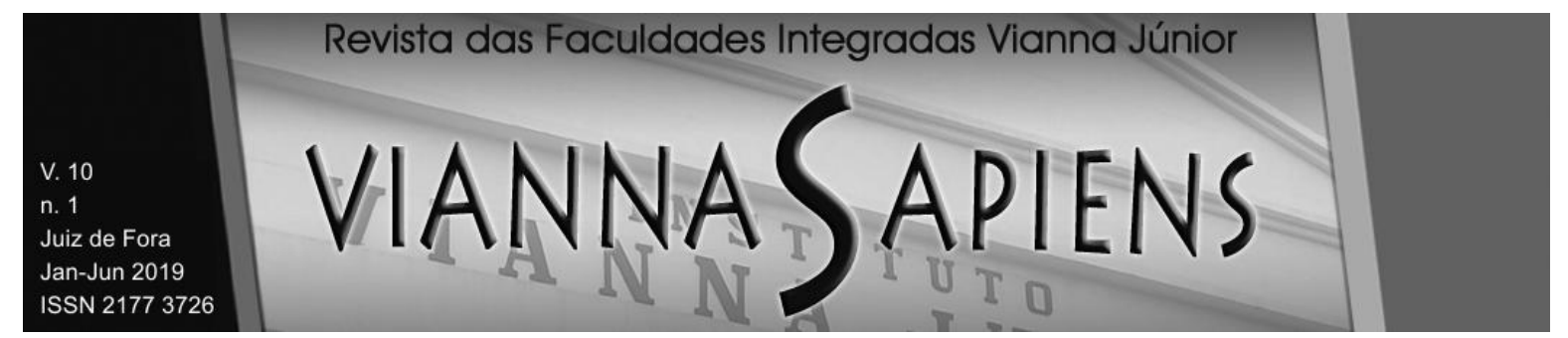

buscam o melhor para si, por meio de um mediador, que será imparcial e não poderá emitir opinião, mas que contribuirá ao aplicar as ferramentas e as técnicas para que as partes vislumbrem o que seria bom para ambas. Nesse sentido, abandona-se a ideia do ganha-perde, indo de encontro com o ganha-ganha, o que vem a favorecer a todos os envolvidos na relação.

Dessa forma, conforme relatado por Roberta Freitas Carvalho dos Santos (2012, p.4),

\begin{abstract}
busca-se como meio de democratizar o acesso à justiça procedimentos mais acessíveis, simples e racionais, mais econômicos, eficientes e adequados a certos tipos de conflito, a promoção de uma espécie de justiça coexistencial, baseada na conciliação e no critério de equidade social distributiva, bem como a criação de formas de justiça mais acessível e participativa, atraindo a ela membros dos variados grupos sociais e buscando a excessiva burocratização.
\end{abstract}

Para complementar, é importante mencionar, ainda, o entendimento do sociólogo e jurista Boaventura de Souza Santos (2011, p.62), uma vez que, conforme relatado pelo mesmo, "a criação de mecanismos de solução de conflitos, caracterizados pela informalidade, rapidez, acesso ativo da comunidade, conciliação e mediação entre as partes constituem a maior inovação da política judiciária".

Portanto, embora um avanço já venha acontecendo, em decorrência também do CPC de 2015, muito ainda há que se percorrer. As opções já estão demonstradas para todos os indivíduos, o que deve ser feito é escolher o caminho a ser seguido da melhor forma, visando uma melhoria na sociedade e, consequentemente, no Poder Judiciário. 


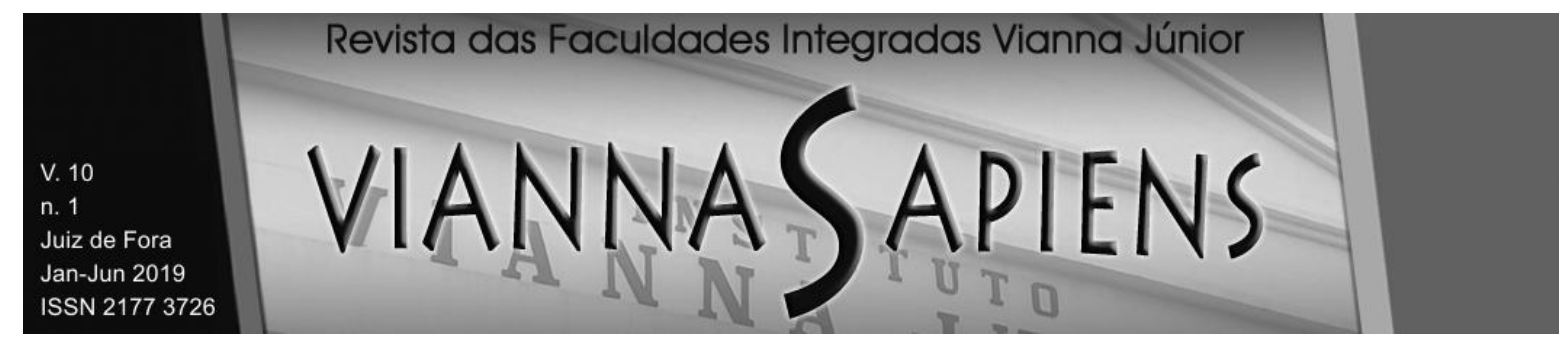

\section{CONCLUSÃO}

Através da análise do Poder Judiciário, há que se mencionar o acesso à justiça, direito fundamental previsto pela Constituição Federal de 1988, o qual permite que as pessoas procurem mencionado poder, a fim de terem seus problemas solucionados. Com base nesse preceito essencial e fundamental para os indivíduos, tem-se que a resposta, por parte do Judiciário, deve ser justa e eficiente, isto é, de maneira a ir ao encontro com os princípios do contraditório, da ampla defesa e do devido processo legal, significando a prestação de uma tutela jurisdicional efetiva e eficaz.

Por conseguinte, ao citar, então, a necessidade e o direito por essa tutela, determinada questão acaba vindo a esbarrar em duas situações encontradas no Poder Judiciário, quais sejam, a sobrecarga desse poder e a morosidade processual. Isso ocorre porque ainda são muitos os indivíduos que vislumbram o juiz como o único capaz de resolver os impasses que possuem. Ainda assim, é possível ressaltar que uma das causas das duas situações expostas é o deferimento da Justiça Gratuita, o qual acaba trazendo inúmeros benefícios para a parte que o detém.

Dessa forma, por não arcarem com as custas processuais, muitas são as pessoas que requerem a concessão desse instituto sem nem ao menos precisarem. Por isso, faz-se essencial uma análise cautelosa, a fim de que seja observada se existe uma real necessidade por elas, isto é, se são hipossuficientes, não tendo condições econômicas de suportar as custas de seu processo. Além disso, o deferimento da Justiça Gratuita, se feito sem observância, acaba por restringir o acesso à justiça daqueles realmente necessitados.

Ainda assim, outra causa da sobrecarga judiciária acaba sendo o exposto acima, isto é, a questão de os indivíduos buscarem o Judiciário, por acreditarem ser, muitas vezes, a única saída que possuem. Contudo, faz-se necessário ressaltar a importância dos meios adequados de resolução de conflitos, os quais foram 


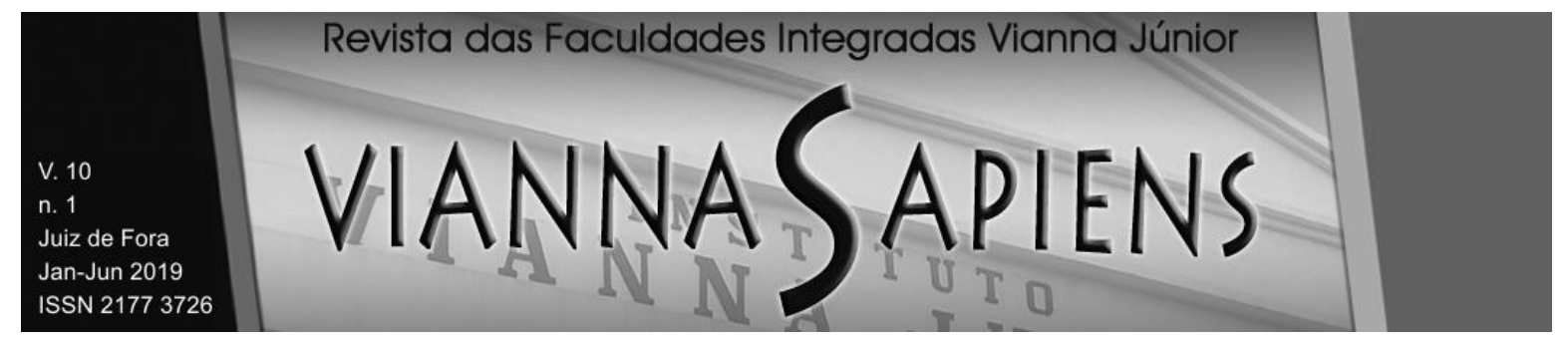

consolidados com o Código de Processo Civil de 2015. Com o uso da Mediação, por exemplo, as partes tornam-se as tomadoras de decisões, as quais acabam por vir delas, o que vem, além de ser produtivo para elas, diminuir o número de demandas no Poder Judiciário.

Dessa forma, é possível relatar, ainda, a facilidade existente para propor uma demanda nesse poder que, junto ao supramencionado, afeta mais o conceito e a prática do acesso à justiça. Portanto, ainda há que se mencionar que, embora a sociedade brasileira já tenha desenvolvido e avançado no tocante ao litígio, muito há a caminhar, para que o Judiciário não seja tido como a única saída para a resolução dos impasses, e, consequentemente, o acesso à justiça possa existir de uma forma mais concreta.

\section{REFERÊNCIAS}

BRASIL. Constituição (1988). Constituição da República Federativa do Brasil. Brasília: DF: Senado, 1988.

BRASIL. Código de Processo Civil (2015). Código de Processo Civil Brasileiro. Brasília, DF: Senado, 2015.

CAPPELLETTI, Mauro; GARTH, Bryant. Acesso à Justiça. Sergio Antonio Fabris Editor. Porto Alegre, 1988.

CARRO, Eric Almeida. O que é Análise Econômica do Direito. Disponível em:<http://jusliberdade.com.br/o-que-e-a-analise-economica-do-direito/>. Acesso em: 27 jun.2018.

CONSELHO NACIONAL DE JUSTIÇA. Justiça em Números 2018. Brasília: CNJ, 2018. Disponível em:< http://www.cnj.jus.br/files/conteudo/arquivo/2018/09/8d9faee7812d35a58cee3d92d2 df2f25.pdf >. Acesso em: 29 nov.2018. 


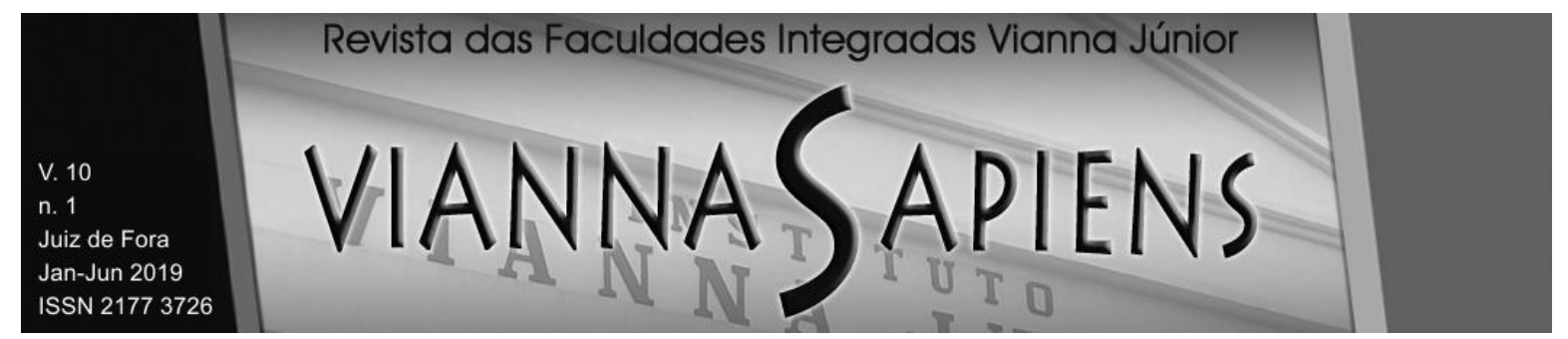

DIAS, Marina Corrêa. Mudança de paradigma: da cultura do litígio à cultura da paz. Disponível

em:<https://marinadias.jusbrasil.com.br/artigos/307945346/mudanca-de-paradigmada-cultura-do-litigio-a-cultura-da-paz>. Acesso em: 27 jun.2018.

FERNANDEZ, Atahualpa. FERNANDEZ, Athus. A "justiça" gratuita no Brasil. 2013. Disponível em:<https://jus.com.br/artigos/24633/a-justica-gratuita-no-brasil/1>. Acesso em: 04 abr.2018.

MENDES, Renato Souza. A morosidade processual frente os direitos fundamentais e a ineficiência da Administração Pública. Disponível em:<https://jus.com.br/artigos/22729/a-morosidade-processual-frente-os-direitosfundamentais-e-a-ineficiencia-da-administracao-publica/2>. Acesso em: 02 nov.2018.

MINOTTO, Arthur Monteiro. Justiça Gratuita e a Assistência Judiciária. Disponível em:<https://www.portaleducacao.com.br/conteudo/artigos/conteudo/justica/56961>. Acesso em: 15 abr.2018.

SALAMA, Bruno Meyerhof. O que é pesquisa em Direito e Economia? Disponível em:<http://bibliotecadigital.fgv.br/dspace/bitstream/handle/10438/2811/caderno\%252 0direito\%252022. pdf?sequence=1\&isAllowed=y>. Acesso em: 20 abr.2018.

SANTOS, Boaventura de Souza. Para uma revolução democrática da justiça. São Paulo: Cortez, 2011, p.62.

SANTOS, Roberta Freitas Carvalho. Acesso à Justiça por meio da mediação de conflitos. Rio de Janeiro: EMERJ, 2012. Disponível em:

<http://www.emerj.tjr.jus.br/paginas/trabalhos_conclusao/2semestre2012/trabalhos_ 22012/RobertaFreitasCarvalhoSantos.pdf>. Acesso em 02 set.2018.

SCHIAVI, Mauro. Manual de Direito Processual do Trabalho. $2^{\mathrm{a}}$ ed. São Paulo: LTR, 2009. 


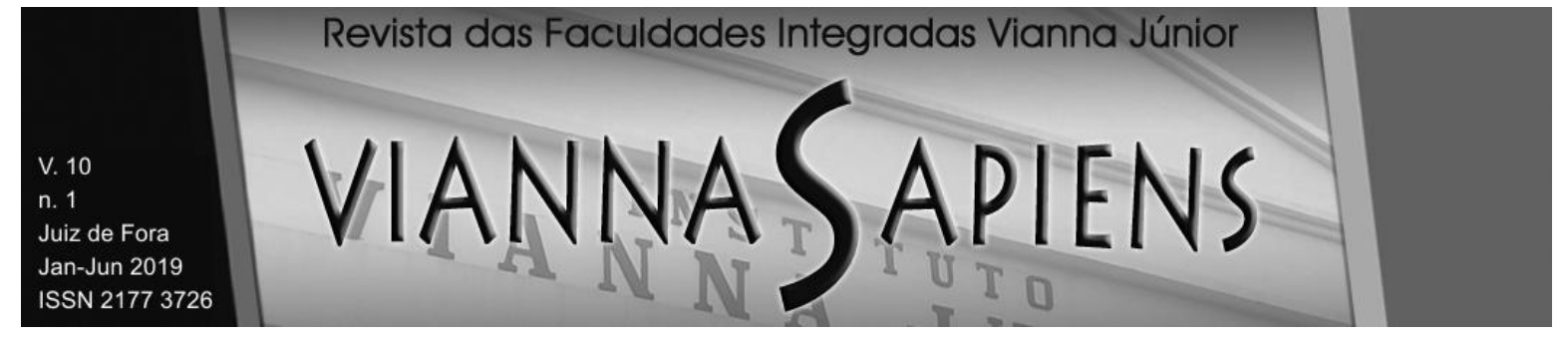

SLAIBI, Nagib Filho. Reforma da Justiça, Editora Impetus, 2005, p. 19.

THIELMANN, Ricardo. As Teorias dos Custos de Transação e as Estruturas de Governanças: uma Análise do Caso do Setor de Suinocultura no Vale do Rio Ipiranga - MG. Disponível

em:<https://www.aedb.br/seget/arquivos/artigos13/991852.pdf>. Acesso em: 30 out.2018.

TOALDO, Adriane Medianeira. A cultura do litígio x a cultura da mediação.

Disponível em: $<$ http://www.ambito-

juridico.com.br/site/?n link=revista artigos leitura\&artigo id=10859\&revista cadern o=21\# ftn2>. Acesso em: 30 out.2018.

TORRES, Ana Flavia Melo. Acesso à justiça. Disponível em:<http://www.ambitojuridico.com.br/site/index.php?n_link=revista_artigos_leitura\&artigo_id=4592>. Acesso em: 15 abr.2018.

THEODORO JUNIOR, Humberto. Revista Síntese "Direito Civil e Processual Civil", Ano VI, n. 36, jul-ago 2005.

VENOSA, Silvio de Salvo. Direito Civil: parte Geral. Vol. 1ํㅜ $12^{\circ}$ ed., Atlas, 2012, p. 70.

WAMBIER, Luiz Rodrigues. Curso avançado de processo civil: teoria geral do processo de conhecimento. 9. Ed. rev., atual. e ampl. São Paulo: Editora Revista dos Tribunais, 2007, p. 321.

Recebido em 13/12/2018

Publicado em 12/07/2019 